\title{
Influence of weather conditions on activity of tropical snakes
}

\author{
G. P. BROWN AND R. SHINE^ \\ Biological Sciences A08, University of Sydney, New South Wales 2006, Australia \\ (Email:rics@bio.usyd.edu.au)
}

\begin{abstract}
There are many anecdotal reports of massive day-to-day variation in activity levels of tropical reptiles and amphibians, and intuition suggests that weather conditions may be responsible for much of that variation. Our analysis of a large data set on the activity levels of tropical snakes and frogs confirms the existence of this short-term variation in activity levels, reveals strong synchrony between sympatric taxa in this respect, but also shows that standard weather variables (temperature, humidity, precipitation, moonlight, atmospheric pressure) are surprisingly poor at predicting the numbers of individuals and species encountered during standardized surveys. We recorded the numbers of snakes and prey taxa (frogs) encountered on 349 nights over the course of one year on a 1.3-km transect in the Adelaide River floodplain, in the wet-dry tropics of Australia. Frogs, water pythons (Liasis fuscus), slatey-grey snakes (Stegonotus cucullatus) and keelbacks (Tropidonophis mairii) all showed strongly seasonal patterns of activity. After adjusting for seasonal differences, encounter rates were related to climatic conditions but different taxa responded to different weather variables. Water python activity was related to amount of moonlight, keelback activity was related to temperature, and frog activity was related to relative humidity, rainfall, temperature and moonlight. However, weather variables explained relatively little of the variation in activity levels. Strong synchrony was evident among encounter rates with various taxa (independent of season and weather conditions), suggesting that activity levels may be determined by other unmeasured factors.
\end{abstract}

Key words: moonlight, precipitation, relative humidity, reptile, synchrony, temperature.

\section{INTRODUCTION}

Every field biologist knows that the rates at which one encounters active animals within a study population can display immense variation at a variety of temporal scales. Conspicuous seasonal peaks in encounter rates are often associated with significant biological events such as hibernation, mate-searching by adult males, egg-laying migrations by gravid females, and hatching of eggs (Lack 1968; Bonnet et al. 1999). The causal bases for varying encounter rates on a seasonal basis may thus be evident (Fleming \& Hooker 1975; Christian \& Bedford 1995). Much more puzzling, however, is the fact that levels of activity can vary dramatically from day to day even within a single season. Intuition suggests that this kind of variation must reflect factors that themselves vary on a short timescale; weather conditions provide the most obvious candidate for such proximate stimuli. Although the inference seems strong, evidence to support it is surprisingly meagre.

Understanding the basis for day-to-day variations in activity levels is interesting not only in its own right, but because of the consequences for population ecology. For example, the proportion of days within a specific season on which an individual is active may well influ-

${ }^{\star}$ Corresponding author.

Accepted for publication April 2002. ence its total food intake (and thus, rates of growth and reproduction) as well as its vulnerability to predators (and hence, mortality schedules). Variation among individuals in terms of the cues eliciting activity may thus contribute significantly to within-population variation in organismal fitness. On a broader spatial scale, we might expect responses in local populations to adapt to local conditions (e.g. the relationship between specific weather conditions, prey availability and predator activity) and, hence, geographical comparisons should reveal intraspecific divergence in such responses. On a more pragmatic level, understanding the determinants of variation in activity levels may enable us to predict optimal times for collecting or observing active animals, and may facilitate the use of counts of active animals as indices of underlying population sizes (Caughley 1977; Caughley \& Sinclair 1994; Gibbs 2000; Sun et al. 2000).

As ectotherms, reptiles are highly dependent on physical exchange with the environment. Most obviously, activity in cold-climate reptile populations is often constrained by ambient temperatures or basking opportunities (i.e. incident solar radiation). Thus, reptiles may shift between nocturnal and diurnal activity depending on seasonal temperature regimes (Mushinsky \& Hebrard 1977; Gibbons \& Semlitsch 1987) and reduce activity on cool or cloudy days (Peterson 1987; Peterson et al. 1993; Nelson \& Gregory 2000). However, the majority of reptile 
species (and individuals) inhabit tropical rather than temperate-zone habitats (Vitt 1987), so their levels of activity are unlikely to be constrained by the need to achieve high body temperatures (Shine \& Madsen 1996). Instead, factors such as moonlight (Madsen \& Osterkamp 1982; Houston \& Shine 1994) and relative humidity or moisture (Henderson \& Hoevers 1977; Dalrymple et al. 1991; Daltry et al. 1998; Sun et al. 2000) may be more important in this respect.

There is little published information on how these short-term weather fluctuations may affect the activity of tropical reptiles (Henderson \& Hoevers 1977; Gibbons \& Semlitsch 1987). During our fieldwork in the seasonally inundated floodplains of tropical Australia, we noticed that rates of encounters with nocturnally active snakes can vary as much from night to night as they do from season to season (Fig. 1). We predicted that climatic factors would explain much of this short-term variation in activity, and the present paper describes our attempt to test that straightforward prediction. Second, because we recorded numbers of frogs active each night, we could also assess whether the activity levels of anuran-eating snakes were correlated with the abundance of anurans. Third, in order to see whether some unmeasured variable might also affect the activity patterns of our study organisms, we examined the degree of synchrony in the activity of different taxa. If common causal factors underlie activity patterns, then we would expect to see that peak encounter rates with one species occur on the same nights as for other taxa. Finally, for one species of snake we had large enough capture samples to examine the activity relationships of males, females and juveniles separately. Because these different classes are often active for different reasons (i.e. reproduction vs feeding), we predicted that they might be active under different environmental conditions.

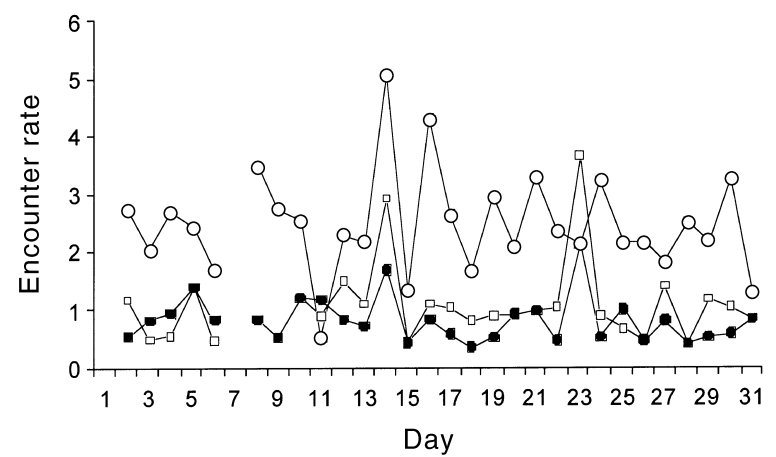

Fig. 1. Daily variation in encounter rates (square root transformed number of snakes per $\mathrm{h}$ ) of $(\mathrm{O})$ water pythons (Liasis fuscus), ( $\square$ ) keelbacks (Tropidonophis mairii) and ( slatey-grey snakes (Stegonotus cucullatus) during October 2000 .

\section{METHODS}

\section{Study site}

The study took place in the Fogg Dam Nature Reserve, $60 \mathrm{~km}$ south-east of Darwin in Australia's Northern Territory. The Fogg Dam wall is a 1.3-km embankment constructed on the Adelaide River floodplain. The area south of the wall contains permanent water and the north side consists of seasonally inundated floodplain. The study area has been described and illustrated in detail elsewhere (Madsen \& Shine 1996).

\section{Study species}

Although the Australian wet-dry tropics contain a diverse reptile fauna, three snake species comprise the majority of specimens seen on the wall of Fogg Dam. The most abundant is the water python (Liasis fuscus), a large (to $3 \mathrm{~m}$ ) heavy-bodied constrictor that feeds primarily on native rats (Madsen \& Shine 1996). Keelbacks (Tropidonophis mairii) are natricine colubrids (to $1 \mathrm{~m}$ in length) that feed primarily on frogs, whereas slatey-grey snakes (Stegonotus cucullatus, to $2 \mathrm{~m}$ ) are colubrines that take a much more varied diet, including rats and frogs (Shine 1991).

\section{Survey methods}

Data on weather conditions and on our rates of encounter with snakes and frogs were collected between 15 June 2000 and 14 June 2001. The dam wall was surveyed on foot and by car for an average of $76 \mathrm{~min}$ (range 20-175 min) beginning at approximately 19.00 hours on 349 nights over the course of 1 year. All snakes seen by spotlight during the surveys were identified and counted. In addition, we attempted to capture all keelbacks and slatey-grey snakes that we saw. Captured snakes were returned to the laboratory, measured, sexed and individually marked and released at their point of capture the next night.

To measure frog abundance each night we established 10 permanent survey grids in which we identified and counted frogs during 334 of the 349 nights on which we surveyed snakes. Each grid enclosed a 2-m section of the bitumen road on the top of the dam wall. The 10 grids were spaced approximately $100 \mathrm{~m}$ apart across the 1300-m length of the dam wall. Thus, we sampled approximately $1.5 \%$ of the top surface of the dam wall for frogs on each visit. Visual inspection of the 10 survey grids required $<60$ s per night $(5-6$ seconds per grid). The most abundant frog species were Litoria bicolor (42\%), L. nasuta (39\%), L. dahlii (17\%) and 
Table 1. Eigenvectors from principal component analysis of daily climatic data

\begin{tabular}{lrrr}
\hline & PC1 & PC2 & PC3 \\
\hline Eigenvalue & 3.33 & 1.21 & 1.01 \\
Percentage variation explained & 41.62 & 15.08 & 12.61 \\
Eigenvectors & & & \\
Mean sea level pressure (hpa) & 0.44 & -0.27 & -0.07 \\
Change in pressure & -0.13 & 0.40 & -0.51 \\
Mean RH (\%) & -0.47 & -0.10 & -0.02 \\
SD RH & 0.43 & 0.31 & 0.02 \\
Mean air temperature (C) & -0.22 & 0.68 & 0.19 \\
SD air temperature & 0.48 & -0.03 & -0.06 \\
Rainfall (mm) & -0.33 & -0.41 & 0.20 \\
Moonlight (\% illuminated) & 0.10 & 0.16 & 0.81 \\
\hline
\end{tabular}

All weather variables except rainfall were measured between 18.00 and 21.00 hours to coincide with the timing of our surveys. RH, relative humidity.
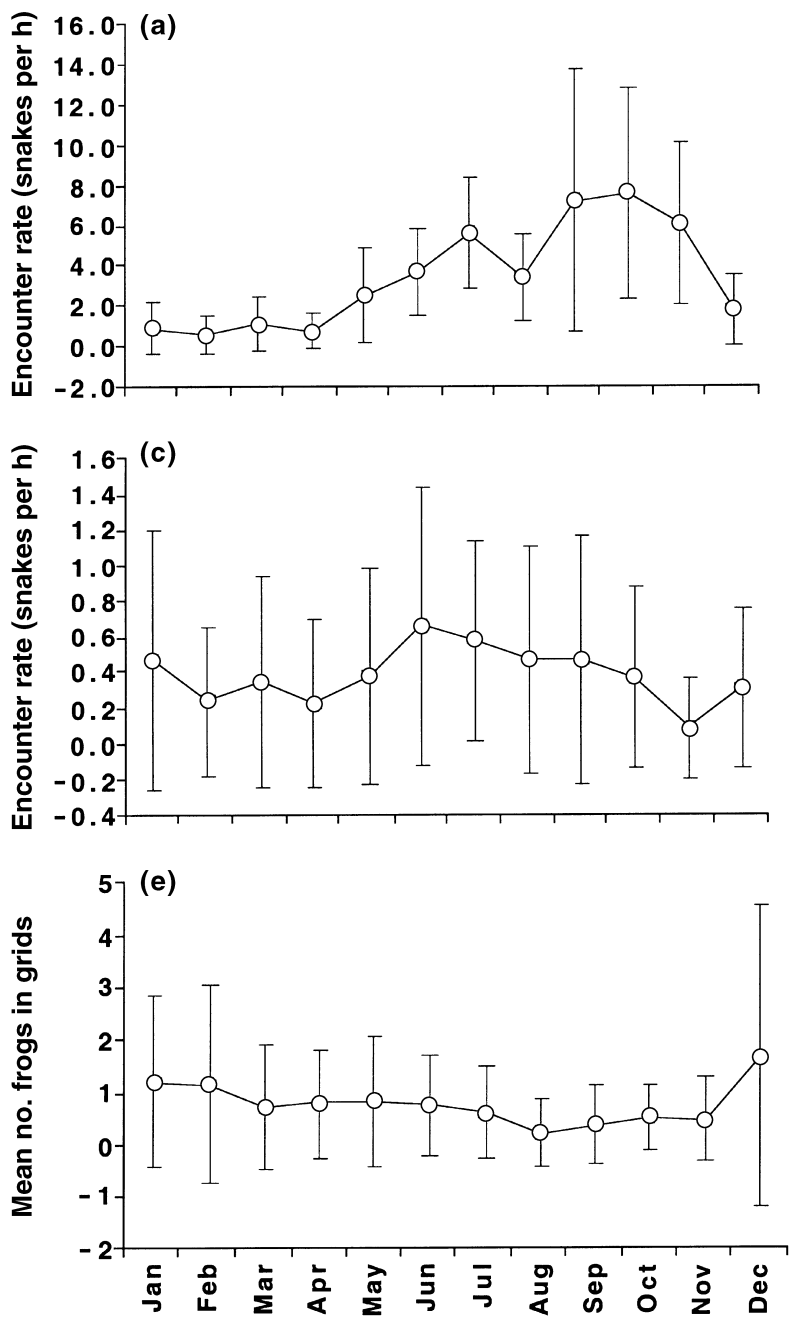

Fig. 2. (a,b,c) Encounter rates with snakes, (d) total number of snake species encountered per nightly survey and (e) counts of frogs per night on the wall of Fogg Dam. Error bars indicate standard deviations. (a) Liasis fuscus; (b) Tropidonophis mairii; (c) Stegonotus cucullatus.
L. rothi $(2 \%)$. Because of the relatively small sample size for each frog species, we pooled the data to give a total frog count for each night.

\section{Climatic data}

Air temperature and relative humidity were recorded hourly on Hobo-temp (Onset Computer Co., Pocasset, MA) dataloggers located at Middle Point village, $1.5 \mathrm{~km}$ from Fogg Dam. Rain was measured daily at a location approximately $2 \mathrm{~km}$ from Fogg Dam. Data on the proportion of the moon illuminated each night and the times of moonrise and set were taken from the Astronomical Applications Department, US Naval Observatory. Data on mean sea level atmospheric pressure were obtained from the Australian Bureau of Meteorology weather station located at the Darwin airport, approximately $50 \mathrm{~km}$ from Fogg Dam.
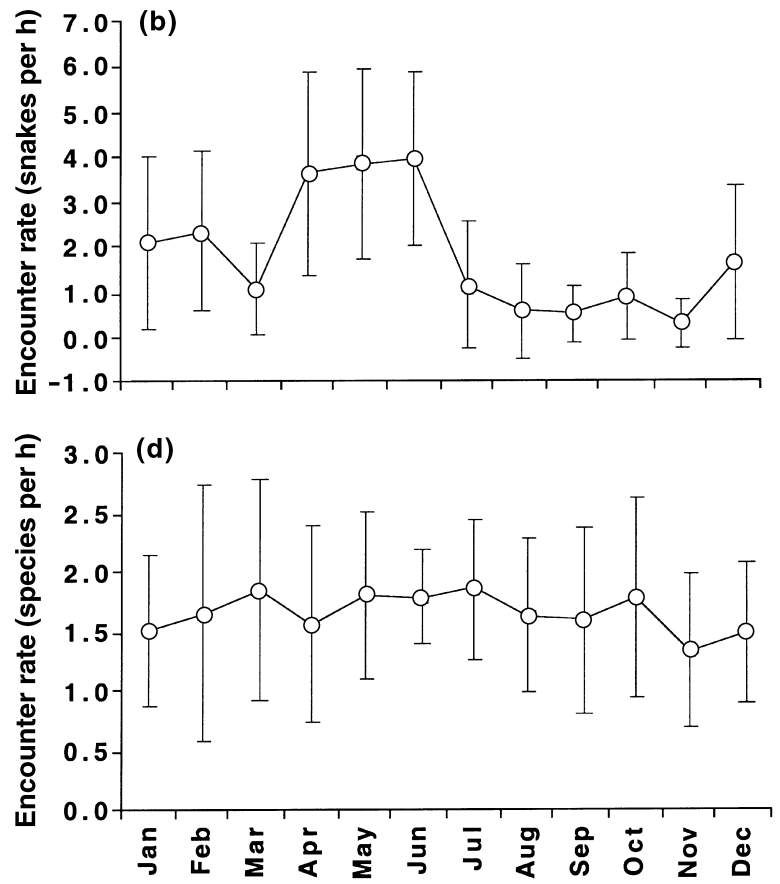
Atmospheric pressure readings were taken at 18.00 and 21.00 hours each evening.

Except for rainfall, only climatic data measured during the evening (18.00-21.00 hours) corresponding to the time of our surveys were used. Data on rainfall encompassed the previous 24-h period. Moon illumination was adjusted to 0 on days when the moon did not rise before 21.00 hours or when it set prior to 17.00 hours. To simplify the weather variables into a smaller number of factors, we subjected the following variables for each evening to principal component analysis: moon illumination, total rainfall, mean air temperature, standard deviation of mean air temperature, mean relative humidity, standard deviation of mean relative humidity, mean atmospheric pressure, and change in atmospheric pressure between 18.00 and 21.00 hours. This method generated three principal components (PC), which together explained $69.3 \%$ of variation in the measured weather variables (Table 1 ). Positive values of PC1 described dry nights with high atmospheric pressure and variable (i.e. rapidly cooling) temperature. PC2 had high loading only on air temperature, and PC3 had high loading on moonlight (Table 1).

\section{Analyses}

To meet the assumptions of ANOVA, count data on the number of snake species encountered each night, the numbers of individual water pythons, keelbacks and slatey-grey snakes and the number of frogs observed in survey grids were transformed using the equation

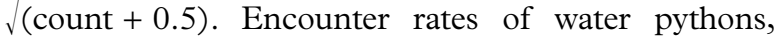
keelbacks and slatey-grey snakes and number of snake species were then calculated by dividing transformed counts by the time spent searching each night. Frog counts were not transformed to rates because the time spent observing frog survey grids was the same each night.

We used multivariate regression to assess simultaneously the effects of the three most important principal components on snake and frog activity. Because the activity of frogs and snakes was also highly seasonal, we included month as a categorical variable in the multiple regressions to remove seasonal effects.

\section{RESULTS}

Between 15 June 2000 and 14 June 2001, we observed a total of 2671 snakes on Fogg Dam on the 349 nights when surveys were carried out. A total of 258 frogs were counted in 10 survey grids over the same period. At least one snake was seen on 338 of 349 (97\%) survey nights. Encounter rates varied from 0 to 26.1 snakes per h for water pythons, 0-9.3 snakes per $\mathrm{h}$ for keelbacks, and 0-3.5 snakes per $\mathrm{h}$ for slatey-grey snakes. Together, water pythons, keelbacks and slateygrey snakes comprised $97.8 \%$ of all snakes seen on Fogg Dam (58.3, 32.4, 7.2\%, respectively). Other snake species encountered during the study and their relative occurrences were: Enhydris polylepis (1\%), Dendrelaphis punctulatus (0.5\%), Pseudechis australis (0.2\%), Liasis childreni (0.2\%), Rhinoplocephalus pallidiceps (0.2\%), Boiga irregularis (0.2\%), Demansia sp. (0.1\%), Morelia spilota (0.04\%) and Furina ornata (0.04\%).

Water pythons were encountered most frequently during September-November (Fig. 2a). Keelbacks occurred in largest numbers during April-June (Fig. 2b). Frogs were encountered more often during December-February (Fig. 2e). The numbers of slateygrey snakes and total number of snake species encountered exhibited less variation among months over the study period than did water pythons, keelbacks or frogs (Figs 2c,d).

\section{Synchrony in activity patterns among snake species}

Simple correlations indicated that our rates of encounter with the three main snake species were significantly positively related to each other during 3-5 months of the 12-month study period. The total number of snake species seen was also correlated with the activity levels of each of the three focal species during most months. Thus, some nights were 'good' for snake activity in general (at least during some months). On nights when many individuals of any of the three focal species were encountered, the other focal taxa were also numerous and additional species were frequently found. Statistical analyses of these patterns will follow, after incorporation of other variables.

\section{Synchrony in activity between predators and prey}

Frog counts were significantly correlated with keelback activity in 6 months of our survey period, and with slatey-grey snake activity in 7 months.

\section{Climatic effects}

\section{Univariate analyses}

Simple correlations between activity levels and weather variables for each month indicated differing patterns among taxa (Table 2). No weather variable had consistently significant effects throughout the year. Activity of water pythons was most often linked to air temperature (significant correlations during 3 months) and 


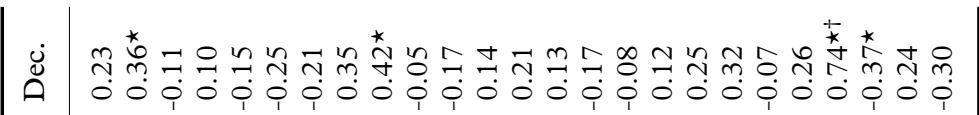

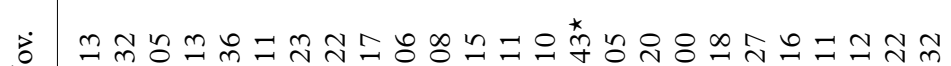

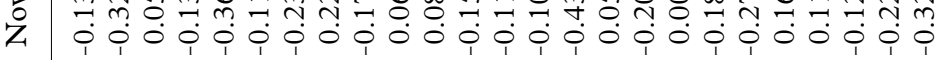

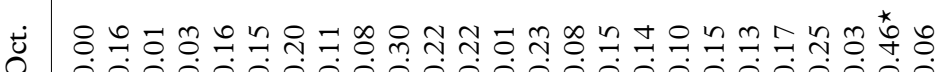

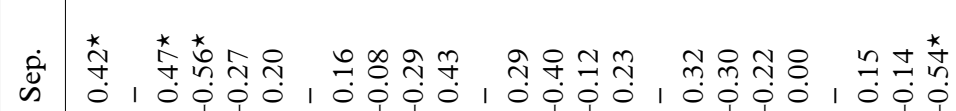

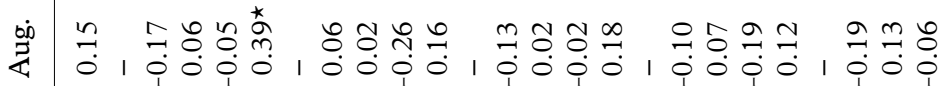

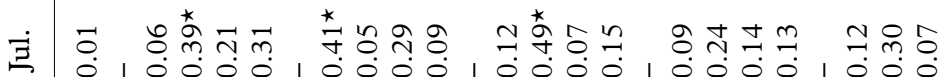

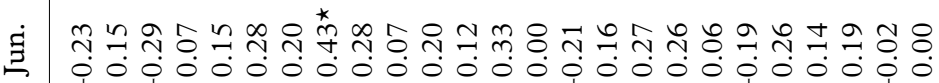

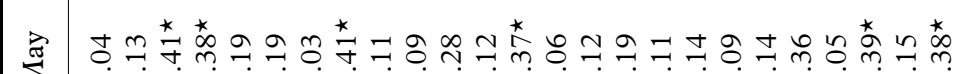

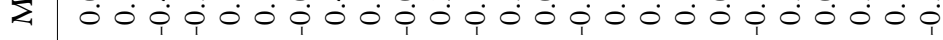

mºํ.

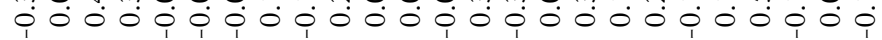

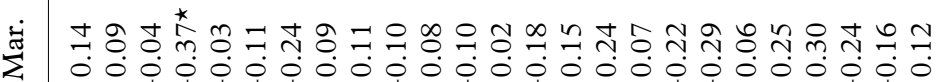

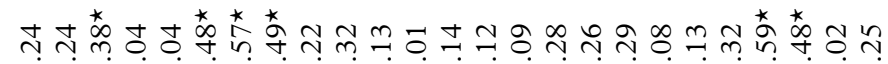

ए人

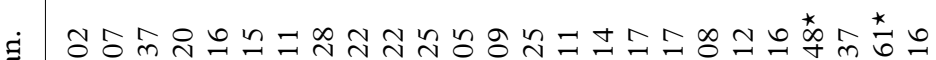
i०o 
moonlight levels (5 months). Keelback activity was correlated with air temperature in 4 months. Slateygrey snake activity and number of snake species encountered were less dependent on weather (Table 2). Frog activity was related to rainfall (4 months) and air temperature (3 months; Table 2).

\section{Multivariate analyses}

Multiple regressions were performed to relate snake and frog activity to the three climatic principal components. To remove the effects of monthly differences in activity levels, month was included in each model as a categorical independent variable. This model explained $39 \%$ of variation in our rates of encounter with water pythons, $31 \%$ in keelbacks, $5 \%$ in slatey-grey snakes and $20 \%$ in frogs (Table 3 ). The regressions also revealed strong interspecific differences in climatic correlates of activity.

After removing monthly effects, the activity of water pythons was significantly negatively related to PC3 (moonlight). Keelback activity was positively related to PC2 (temperature). The total number of snake species encountered was not significantly linked to any weather PC. Frog counts were significantly negatively related to PC1 and PC2, and positively related to PC3 (Table 3).

\section{Expanded multivariate analysis}

There is an apparent contradiction in our findings that there are common 'good' nights for snakes and frogs on one hand, and the fact that snake species and frog activity levels respond to different environmental cues on the other hand. To resolve this paradox, we constructed a series of full multivariate models with the activity levels of each species as dependent variables and month, climate principal components and activity levels of other taxa as independent variables. The activity levels of other taxa were included in the full models as proxies for unmeasured causative factors, not because they are likely to affect the activity of the dependent species. Thus these models simultaneously incorporated seasonal effects, climatic effects and correlated variables affecting the activity of other species.

For water pythons, keelbacks and frogs these full models revealed the same patterns of significant weather principal components as the simpler models, in addition to various significant relationships with activity levels of other taxa. For slatey-grey snakes and number of snake species, the full models revealed weather effects not apparent in the simpler models. In both cases, the effects of PC2 on activity became statistically significant (Table 4). Significance levels for

Table 3. Multiple regression analyses of the effects of seasonal and climatic factors on encounter rates of snakes and frogs at Fogg Dam

\begin{tabular}{|c|c|c|c|c|c|c|}
\hline Dependent variable & Source & d.f. & $\begin{array}{l}\text { Parameter } \\
\text { estimate }\end{array}$ & $F$ & $P$ & Model $R^{2}$ \\
\hline \multirow[t]{5}{*}{ Water python activity } & Month & 11 & & 15.02 & $<0.0001^{\star}$ & 0.39 \\
\hline & PC1 & 1 & 0.01 & 0.03 & 0.86 & \\
\hline & PC2 & 1 & -0.06 & 1.63 & 0.21 & \\
\hline & PC3 & 1 & -0.08 & 3.97 & $0.047^{\star}$ & \\
\hline & Error & 319 & & & & \\
\hline \multirow[t]{5}{*}{ Keelback activity } & Month & 11 & & 12.86 & $<0.0001^{\star}$ & 0.31 \\
\hline & PC1 & 1 & 0.00 & 0.00 & 0.99 & \\
\hline & PC2 & 1 & 0.13 & 13.99 & $0.0002^{\star}$ & \\
\hline & PC3 & 1 & 0.03 & 0.78 & 0.38 & \\
\hline & Error & 319 & & & & \\
\hline \multirow[t]{5}{*}{ Slatey-grey snake activity } & Month & 11 & & 1.50 & 0.13 & 0.05 \\
\hline & PC1 & 1 & -0.03 & 3.07 & 0.08 & \\
\hline & PC2 & 1 & 0.03 & 1.58 & 0.21 & \\
\hline & PC3 & 1 & 0.00 & 0.00 & 0.97 & \\
\hline & Error & 319 & & & & \\
\hline \multirow[t]{5}{*}{ Snake species activity } & Month & 11 & & 1.20 & 0.29 & 0.04 \\
\hline & PC1 & 1 & -0.01 & 0.05 & 0.83 & \\
\hline & PC2 & 1 & -0.00 & 0.00 & 0.99 & \\
\hline & PC3 & 1 & 0.01 & 0.15 & 0.70 & \\
\hline & Error & 319 & & & & \\
\hline \multirow[t]{5}{*}{ Frog activity } & Month & 11 & 0. & 0.57 & 0.85 & 0.20 \\
\hline & PC1 & 1 & -0.13 & 12.15 & $0.0006^{\star}$ & \\
\hline & PC2 & 1 & -0.14 & 12.06 & $0.0006^{\star}$ & \\
\hline & PC3 & 1 & 0.12 & 12.68 & $0.0004^{\star}$ & \\
\hline & Error & 305 & & & & \\
\hline
\end{tabular}

\footnotetext{
${ }^{\star}$ Significant at $P<0.05$. Activity refers to the number of snakes, or snake species, encountered per hour.
} 
these regressions were determined from type III sums of squares, which assess the significance of each factor after variation attributable to all other variables in the model has been accounted for. Thus, the significant relationships among activity levels of different taxa are independent of any common relationship to any weather variable.

\section{Intraspecific comparisons}

The activity of all three classes of keelbacks (adult males, adult females and juveniles) varied among months and was related to snake species activity. Activity patterns of adult males and juveniles were significantly affected by PC2 (temperature). Activity of

Table 4. Multiple regression analyses of the effects of season, climate, and activity of other taxa on our rates of encounter with snakes and frogs at Fogg Dam

\begin{tabular}{|c|c|c|c|c|c|}
\hline Dependent variable & Source & d.f. & $F$ & $P$ & Model $R^{2}$ \\
\hline \multirow[t]{9}{*}{ Water python activity } & Month & 11 & 12.91 & $<0.0001^{\star}$ & 0.60 \\
\hline & PC1 & 1 & 0.95 & 0.33 & \\
\hline & PC2 & 1 & 0.30 & 0.59 & \\
\hline & PC3 & 1 & 8.66 & $0.0035^{\star}$ & \\
\hline & Keelback activity & 1 & 7.77 & $0.0057^{\star}$ & \\
\hline & Slatey-grey snake activity & 1 & 2.39 & 0.12 & \\
\hline & Snake species activity & 1 & 71.52 & $<0.0001^{\star}$ & \\
\hline & Frog activity & 1 & 1.09 & 0.30 & \\
\hline & Error & 301 & & & \\
\hline \multirow[t]{9}{*}{ Keelback activity } & Month & 11 & 20.29 & $<0.0001^{\star}$ & 0.66 \\
\hline & PC1 & 1 & 0.19 & 0.66 & \\
\hline & PC2 & 1 & 39.31 & $<0.0001^{\star}$ & \\
\hline & PC3 & 1 & 0.03 & 0.84 & \\
\hline & Water python activity & 1 & 7.77 & $0.0057 \star$ & \\
\hline & Slatey-grey snake activity & 1 & 13.43 & $0.0003^{\star}$ & \\
\hline & Snake species activity & 1 & 137.32 & $<0.0001^{\star}$ & \\
\hline & Frog activity & 1 & 1.37 & 0.24 & \\
\hline & Error & 301 & & & \\
\hline \multirow[t]{9}{*}{ Slatey-grey snake activity } & Month & 11 & 1.85 & $0.046^{\star}$ & 0.56 \\
\hline & PC1 & 1 & 3.19 & 0.08 & \\
\hline & PC2 & 1 & 8.50 & $0.0038^{\star}$ & \\
\hline & PC3 & 1 & 1.07 & 0.30 & \\
\hline & Keelback activity & 1 & 13.43 & $0.0003^{\star}$ & \\
\hline & Water Python activity & 1 & 2.39 & 0.12 & \\
\hline & Snake species activity & 1 & 163.93 & $<0.0001^{\star}$ & \\
\hline & Frog activity & 1 & 3.80 & 0.052 & \\
\hline & Error & 301 & & & \\
\hline \multirow[t]{9}{*}{ Snake species activity } & Month & 11 & 4.85 & $<0.0001^{\star}$ & 0.76 \\
\hline & PC1 & 1 & 2.29 & 0.13 & \\
\hline & PC2 & 1 & 5.21 & $0.023^{\star}$ & \\
\hline & PC3 & 1 & 0.41 & 0.52 & \\
\hline & Keelback activity & 1 & 137.32 & $<0.0001^{\star}$ & \\
\hline & Slatey-grey snake activity & 1 & 163.93 & $<0.0001^{\star}$ & \\
\hline & Water python activity & 1 & 71.53 & $<0.0001^{\star}$ & \\
\hline & Frog activity & 1 & 12.55 & $0.0005^{\star}$ & \\
\hline & Error & 301 & & & \\
\hline \multirow[t]{9}{*}{ Frog activity } & Month & 11 & 1.45 & 0.15 & 0.43 \\
\hline & PC1 & 1 & 12.04 & $0.006^{\star}$ & \\
\hline & PC2 & 1 & 19.91 & $<0.0001^{\star}$ & \\
\hline & PC3 & 1 & 14.86 & $0.0001^{\star}$ & \\
\hline & Keelback activity & 1 & 1.37 & 0.24 & \\
\hline & Slatey-grey snake activity & 1 & 3.80 & 0.052 & \\
\hline & Water python activity & 1 & 1.09 & 0.30 & \\
\hline & Snake species activity & 1 & 12.55 & $0.0005^{\star}$ & \\
\hline & Error & 301 & & & \\
\hline
\end{tabular}

${ }^{\star}$ Significant at $P<0.05$. Activity refers to the number of snakes, or snake species, encountered per hour. 
adult females was affected by PC1 (dry, rapidly cooling nights). Activity levels of adult males and females were also related to frog activity (Table 5).

\section{DISCUSSION}

The numbers of snakes that we encountered on the wall of Fogg Dam varied greatly among nights (range 0-26.1 snakes per h), despite the consistency in our methods and in the times that we conducted the surveys. Much of this variation was related to longterm (seasonal) factors, with more than 10-fold differences in mean encounter rates among months for both keelbacks and water pythons (Figs 2a,b). Shorter-term factors were less important, with our measures of weather conditions being surprisingly poor at predicting snake counts. Thus, for example, ANOVA that included only month as a factor explained $39 \%$ of the variance in encounter rates with water pythons. Including all three climatic factors from the principal components analysis (PCA) added $<1 \%$ to this explanatory power (Table 3 ), and adding data on other species added a further $21 \%$ (Table 4). Equivalent numbers for keelbacks were 28, 3 and 35\%; for slateygrey snakes, 3,2 and $51 \%$; for number of snake species in total, 4, <1 and 72\%; and for frog activity, 6, 14 and $23 \%$.

In each of these cases, encounter rates are clearly not random: our multiple regressions with all factors included explained $56-76 \%$ of the variance in nightly encounter rates for all snake-related variables (Table 4). However, only a tiny fraction of that explanatory power was derived from our measures of climatic variables $(\leq 5 \%$ for snake activity dependent variables). Instead, the majority of variance in encounter rates was explicable by:

1. Seasonal (monthly) factors. For two of the three focal snake species, encounter rates shifted considerably among months (Fig. 2). Analysis of a previous data set on this system suggests that these variations may relate to several factors, including reproductive seasonality and food availability (Brown et al. 2001). Unless these seasonal effects are removed from the data sets statistically, other shorter-term influences cannot be identified. For example, water pythons were more common at Fogg Dam during September-October than at other times of the year. Unless this temporal bias was controlled for in analyses, it would have appeared that python activity is driven solely by climatic conditions that predominate during

Table 5. Multiple regression analyses of the effects of season, climate, and activity of other taxa on encounter rates of adult male, adult female and juvenile keelbacks

\begin{tabular}{|c|c|c|c|c|c|}
\hline Dependent variable & Source & d.f. & $F$ & $P$ & Model $R^{2}$ \\
\hline \multirow[t]{9}{*}{ Adult male activity } & Month & 11 & 4.26 & $<0.0001^{\star}$ & \multirow[t]{9}{*}{0.51} \\
\hline & PC1 & 1 & 0.50 & 0.48 & \\
\hline & PC2 & 1 & 9.15 & $0.0027 \star$ & \\
\hline & PC3 & 1 & 1.79 & 0.18 & \\
\hline & Water python activity & 1 & 8.21 & $0.0045^{\star}$ & \\
\hline & Slatey-grey snake activity & 1 & 0.16 & 0.69 & \\
\hline & Snake species activity & 1 & 69.46 & $<0.0001^{\star}$ & \\
\hline & Frog activity & 1 & 17.66 & $<0.0001^{\star}$ & \\
\hline & Error & 301 & & & \\
\hline \multirow[t]{9}{*}{ Adult female activity } & Month & 11 & 11.45 & $<0.0001^{\star}$ & \multirow[t]{9}{*}{0.54} \\
\hline & PC1 & 1 & 7.42 & $0.0068^{\star}$ & \\
\hline & PC2 & 1 & 1.13 & 0.29 & \\
\hline & PC3 & 1 & 0.88 & 0.35 & \\
\hline & Water python activity & 1 & 0.90 & 0.34 & \\
\hline & Slatey-grey snake activity & 1 & 0.27 & 0.61 & \\
\hline & Snake species activity & 1 & 49.49 & $<0.0001^{\star}$ & \\
\hline & Frog activity & 1 & 21.91 & $<0.0001^{\star}$ & \\
\hline & Error & 301 & & & \\
\hline \multirow[t]{9}{*}{ Juvenile activity } & Month & 11 & 5.23 & $<0.0001^{\star}$ & \multirow[t]{9}{*}{0.59} \\
\hline & PC1 & 1 & 0.08 & 0.77 & \\
\hline & PC2 & 1 & 7.39 & $0.0069^{\star}$ & \\
\hline & PC3 & 1 & 0.22 & 0.64 & \\
\hline & Water python activity & 1 & 0.74 & 0.39 & \\
\hline & Slatey-grey snake activity & 1 & 1.06 & 0.31 & \\
\hline & Snake species activity & 1 & 91.81 & $<0.0001^{\star}$ & \\
\hline & Frog activity & 1 & 1.76 & 0.19 & \\
\hline & Error & 301 & & & \\
\hline
\end{tabular}

* Significant at $P<0.05$. Activity refers to the number of snakes, or snake species, encountered per hour. 
September-October. Similar seasonal shifts in activity pattern are very widespread among snakes (Gibbons \& Semlitsch 1987; Dalrymple et al. 1991; Bonnet et al. 1999) and, thus, need to be considered before analysing shorter-term temporal variation in activity rates.

2. Unmeasured proximate factors. The strong synchrony among taxa in activity patterns suggests that some unmeasured factor (or factors) affects activity levels. We do not know what this factor might be, but it is clearly not humidity, rainfall, temperature, atmospheric pressure or moonlight. It may not be a single factor: for example, keelback activity was significantly and independently related to activity levels of both water pythons and slateygrey snakes. We also examined possible interactions among these factors, and non-linearities in the effects. None of these analyses enhanced the explanatory power provided by our weather variables. We also examined possible time-lags in such effects, by comparing encounter rates to weather conditions the day before the survey, the day before that, and so forth. Again, none of these lagged variables explained as much variance in activity patterns as did the weather variables measured on the day of survey.

Although the proportion of variance in encounter rates explained by measured weather variables was low, it was nonetheless highly significant statistically. The specific causal mechanisms (e.g. linking water python activity to moonlight, and keelback activity to temperature) remain obscure. The responses of frog activity to PC1 and PC2 indicate that they prefer moister, cool nights, which is consistent with their avoidance of desiccating conditions (Shoemaker et al. 1992). The preference of frogs for moonlit nights may be related to their dependence on vision. Perhaps the most interesting result is the strong interspecific variation in responses to each of the three major weather variables identified by our PCA (Table 1). Thus, despite their sympatry and broad similarity in foraging mode, the three focal snake species responded in different ways to changing weather conditions.

Even within a single species, the activities of males, females and juveniles do not appear to respond to identical cues. This finding is not unexpected, however, because different age/sex classes may be active for different reasons. The activity of immature individuals is probably related mainly to feeding. The activity of males may involve a large component of mate searching (males are reproductively active all year round, G. P. Brown, unpubl. data) as well as feeding. Adult female keelbacks encountered at Fogg Dam often appeared to be searching for oviposition sites, at least between May and November (Brown \& Shine 2002). These age and sex differences in activity were also apparent in seasonal trends in activity (Brown et al. 2001).
Given this intra- and interspecific diversity in responses, the overall synchrony in activity levels is remarkable. The best biological predictor of our encounter rate with any given species was our rate of encounter with other taxa (Tables 4,5). There was equivocal evidence that predator activity was related to prey activity. Slatey-grey snake activity was not related to frog activity (Table 4). The activity levels of both male and female keelbacks were related to frog activity but the activity of juveniles was not (Table 5), and overall keelback activity was not (Table 4). Most snake biologists anecdotally report 'good nights' for collecting, and our data provide empirical corroboration of such reports. There are indeed nights when an observer will encounter not only many snake species, but also large numbers of individuals of several such species. Unfortunately, the causal mechanisms for this effect remain obscure, and thus we cannot predict the timing of such events. Given the importance of activity levels both for an organism's biology, and for the methodologies required to census populations with maximal efficiency, further research to identify these elusive cues would be of great interest.

\section{ACKNOWLEDGEMENTS}

Logistical support was provided by staff of the Beatrice Hill Farm, notably E. Cox, L. Humphris and K. Levey. The study was funded by the Australian Research Council.

\section{REFERENCES}

Astronomical Applications Department, US Naval Observatory. Data services. Available from: http://aa.usno.navy.mil/AA/ data/

Bonnet X., Naulleau G. \& Shine R. (1999) The dangers of leaving home: Dispersal and mortality in snakes. Biol. Conserv. 89, 39-50.

Brown G. P. \& Shine R. (2002) Reproductive ecology of a tropical natricine snake, Tropidonophis mairii (Colubridae). 7. Zool. (Lond.) in press.

Brown G. P., Shine R. \& Madsen T. (2001) Responses of three sympatric snake species to tropical seasonality in northern Australia. F. Trop. Ecol. in press.

Caughley G. (1977) Analysis of Vertebrate Populations. Wiley \& Sons, New York.

Caughley G. \& Sinclair A. R. E. (1994) Wildlife Ecology and Management. Blackwell Science, Boston.

Christian K. A. \& Bedford G. A. (1995) Seasonal changes in thermoregulation by the frillneck lizard, Chlamydosaurus kingii, in tropical Australia. Ecology 76, 124-32.

Dalrymple G. H., Steiner T. M., Nodell R. J. \& Bernardino F. S. J. (1991) Seasonal activity of the snakes of Long Pine Key, Everglades national park, Florida. Copeia 1991, 294-302.

Daltry J. C., Ross T., Thorpe R. S. \& Wuster W. (1998) Evidence that humidity influences snake activity patterns: A field study of the Malayan pit viper Calloselasma rhodostoma. Ecography 21, 25-34. 
Fleming T. H. \& Hooker R. S. (1975) Anolis cupreus: The response of a lizard to tropical seasonality. Ecology 56, $1243-61$.

Gibbons J. W. \& Semlitsch R. D. (1987) Activity patterns. In Snakes: Ecology and Evolutionary Biology (eds R. A. Seigel, J. T. Collins \& S. S. Novak) pp. 396-421. Macmillan, New York.

Gibbs J. P. (2000) Monitoring populations. In: Research Techniques in Animal Ecology. Controversies and Consequences (eds L. Boitani \& T. Fuller) pp. 213-52. Columbia University Press, NewYork.

Henderson R. W. \& Hoevers L. G. (1977) The seasonal incidence of snakes at a locality in northern Belize. Copeia 1977, 349-55.

Houston D. L. \& Shine R. (1994) Movements and activity patterns of Arafura filesnakes (Serpentes: Acrochordidae) in tropical Australia. Herpetologica 50, 349-57.

Lack D. (1968) Ecological Adaptations for Breeding in Birds. Methuen, London.

Madsen T. \& Osterkamp M. (1982) Notes on the biology of the fish-eating snake Lycodonomorphus bicolor in Lake Tanganyika. F. Herpetol. 16, 185-8.

Madsen T. \& Shine R. (1996) Seasonal migration of predators and prey: Pythons and rats in tropical Australia. Ecology 77, 149-56.

Mushinsky H. R. \& Hebrard J. J. (1977) The use of time by sympatric water snakes. Can. F. Zool. 55, 1545-50.

Nelson K. J. \& Gregory P. T. (2000) Activity patterns of garter snakes, Thamnophis sirtalis, in relation to weather conditions at a fish hatchery on Vancouver Island, British Columbia. 7. Herpetol. 34, 32-40.

Peterson C. R. (1987) Daily variation in the body temperatures of free-ranging garter snakes. Ecology 68, 160-9.

Peterson C. R., Gibson A. R. \& Dorcas M. E. (1993) Snake thermal ecology: The causes and consequences of bodytemperature variation. In: Snakes: Ecology and Behavior (eds R. A. Seigel \& J. T. Collins) pp. 241-314. McGraw-Hill, New York.

Shine R. (1991) Strangers in a strange land: Ecology of the Australian colubrid snakes. Copeia 1991, 120-31.

Shine R. \& Madsen T. (1996) Is thermoregulation unimportant for most reptiles? An example using water pythons (Liasis fuscus) in tropical Australia. Physiol. Zool. 69, 252-69.

Shoemaker V. H., Hillman S. S., Hillyard S. D. et al. (1992) Exchange of water, ions, and respiratory gases in terrestrial amphibians. In: Environmental Physiology of the Amphibians (eds M. E. Feder \& W. W. Burggren) pp. 125-50. University of Chicago Press, Chicago.

Sun L., Shine R., Zhao D. \& Tang Z. (2000) Biotic and abiotic influences on activity patterns of insular pit-vipers (Gloydius shedaoensis, Viperidae) from north-eastern China. Biol. Conserv. 97, 387-98.

Vitt L. J. (1987) Communities. In: Snakes: Ecology and Evolutionary Biology (eds R. A. Seigel, J. T. Collins \& S. S. Novak) pp. 335-65. Macmillan, New York. 